\title{
Selective solvent capture by molecular assemblies of diosmium sawhorses
}

\author{
Gregory L. Powell and Cynthia B. Powell
}

Department of Chemistry \& Biochemistry, Abilene Christian University, ACU Box 28132, Abilene, Texas 79699-8132, USA, powellg@acu.edu

At high temperatures, $\mathrm{Os}_{3}(\mathrm{CO})_{12}$ reacts with monocarboxylic acids to form the diosmium(l) compounds $\mathrm{Os}_{2}(\mu \text {-carboxylate })_{2}(\mathrm{CO})_{6}$ known as sawhorse complexes in which four $\mathrm{CO}$ ligands form legs that extend from the osmium-osmium vector that represents the top of the sawhorse $[1,2]$. Dicarboxylic acids have also been used to prepare compounds in which dicarboxylate (DCA) anions bridge several diosmium sawhorses, including tetranuclear $\left[\mathrm{Os}_{2}(\mathrm{CO})_{6}\right]_{2}(\mu-$ $\mathrm{DCA})_{2}(\mathrm{CO})_{6}$ complexes with two $\mathrm{Os}_{2}$ sawhorse units linked together into a single molecular loop and hexanuclear $\left[\mathrm{Os}_{2}(\mathrm{CO})_{6}\right]_{3}(\mu-\mathrm{DCA})_{3}$ complexes with three $\mathrm{Os}_{2}$ sawhorse units linked together in a triangular geometry [3].

We have recently been able to use 2,6-naphthalenedicarboxylic acid to provide a larger DCA anion that allowed for the isolation of the first example of an octanuclear osmium complex with four $\mathrm{Os}_{2}$ sawhorse units linked together to form a molecular square of the type $\left[\mathrm{Os}_{2}(\mathrm{CO})_{6}\right]_{4}(\mu-$ DCA $)_{4}$ (Fig. 1a). Using benzene-1,3,5-tricarboxylic acid $\left(\mathrm{H}_{3} \mathrm{BTC}\right)$, we have also synthesized the first dodecanuclear osmium complex with six $\mathrm{Os}_{2}$ sawhorse units linked together to form a molecular octahedron with the formula $\left[\mathrm{Os}_{2}(\mathrm{CO})_{6}\right]_{6}(\mu-\mathrm{BTC})_{3}(\mathrm{Fig}$. 1b). The X-ray crystal structures and solvent-capturing propensities of these new MOF-like complexes will be discussed. Dichloromethane molecules occupy the centers of the Os ${ }_{12}$ octahedra, while hexane molecules occupy the large intermolecular voids. Dichloromethane molecules also fill the centers of the $\mathrm{Os}_{6}$ triangles, but not the $\mathrm{Os}_{8}$ squares.

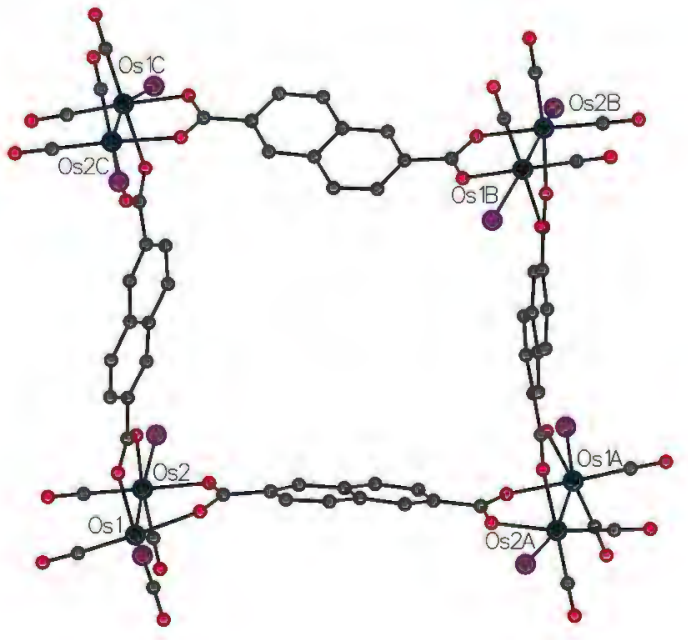

(a)

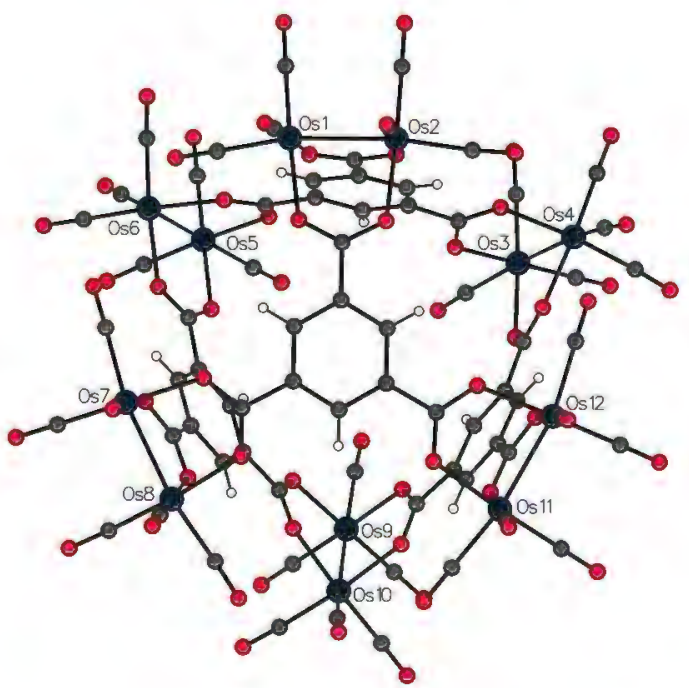

(b)

Fig. 1. The core portions of $(a)$ the $\left[\mathrm{Os}_{2}(\mathrm{CO})_{6}\right]_{4}(\mu-\mathrm{DCA})_{4}$ molecular square and $(\mathrm{b})$ the $\left[\mathrm{Os}_{2}(\mathrm{CO})_{6}\right]_{6}(\mu-\mathrm{BTC})_{3}$ molecular octahedron. 


\section{References}

[1] Crooks, G. R., Johnson, B. F. G., Lewis, J., Williams, I. G. \& Gamlen, G. (1969). J. Chem. Soc. A, 2761-2766.

[2] Pyper, K. J., Jung, J. Y., Newton, B. S., Nesterov, V. N. \& Powell, G. L. (2013). J.

Organomet. Chem. 723, 103-107.

[3] Gwini, N., Marolf, D. M., Yoon, S. H., Fikes, A. G., Dugan, A. C., Powell, G. L., Lynch, V. M., Nesterov, V. N. \& McCandless, G. T. (2017). J. Organomet. Chem. 849-850, 324-331. 